\title{
Editorial: Selected papers on drug synthesis and analysis
}

\author{
Pavel Mucaji ${ }^{1}$. Norbert Haider ${ }^{2} \cdot$ Josef Jampilek $^{3}$ (I)
}

Received: 28 March 2018/Accepted: 3 April 2018/Published online: 18 April 2018

(C) Springer-Verlag GmbH Austria, part of Springer Nature 2018

The independent Faculty of Pharmacy of Comenius University was officially established on September 1, 1952; however, the study of modern pharmacy in Slovakia started already in the academic year 1939-1940 within a study programme organised by the Faculty of Arts and the Faculty of Medicine of the same university. The Conference on the 65th Anniversary of the Faculty of Pharmacy of Comenius University in Bratislava was organized in this connection on September 5-8, 2017. Within this occasion, the traditional Czech and Slovak symposium "Drug Synthesis and Analysis" was organized but not only as a local "Czechoslovakian" meeting but as a full-value international conference, the 46th EuroCongress on Drug Synthesis and Analysis (ECDSA-2017), https://sites.google. com/site/cfph2017 (see logo of the conference in Fig. 1), with 190 active participants from 20 countries from all around the world, including Poland, Austria, Hungary, Bulgaria, Greece, Serbia, Croatia, Slovenia, Italy, Switzerland, France, Luxembourg, Belgium, South Africa, Uzbekistan, China, Republic of Korea, and USA in addition to the Slovak Republic and the Czech Republic. Participants could listen to 27 plenary lectures, get acquainted with a number of oral and poster presentations and participate in a special workshop devoted to drug lifecycle management and in vitro release testing of drug dosage forms. Thus, the symposium was useful not only for

Pavel Mucaji

mucaji@fpharm.uniba.sk

$\triangle$ Norbert Haider

norbert.haider@univie.ac.at

$\triangle$ Josef Jampilek

josef.jampilek@gmail.com

1 Dean of the Faculty of Pharmacy, Comenius University in Bratislava, Bratislava, Slovakia

2 Department of Pharmaceutical Chemistry, University of Vienna, Althanstraße 14, 1090 Vienna, Austria

3 Department of Pharmaceutical Chemistry, Faculty of Pharmacy, Comenius University in Bratislava, Bratislava, Slovakia

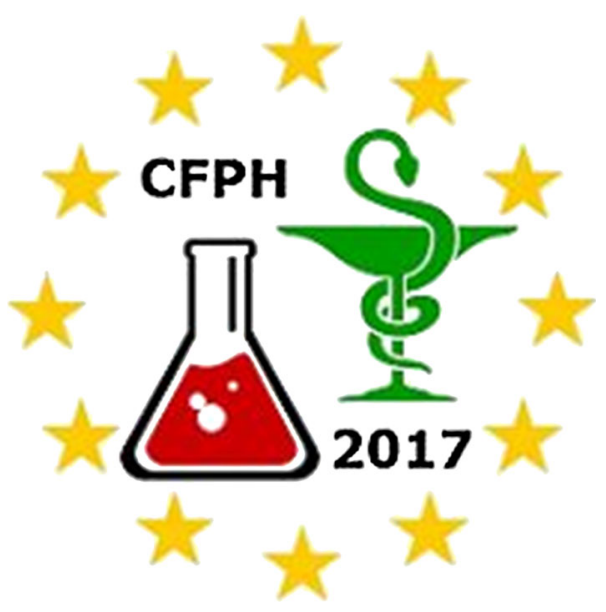

Fig. 1 Logo of conference

scientists but also for researchers from the pharmaceutical industry or staffs of drug regulatory authorities. Therefore, it can be stated that the conference did not only specifically address synthesis and analysis of drugs but covered in fact all topics from drug design to drug registration and the above-mentioned drug lifecycle management. It can be stated that at present, all processes from discovery of a new active pharmaceutical ingredient to the following successful launch of the new drug are interconnected and cannot be understood as isolated issues.

In general, the conference was focused on the following research topics: drug design, research and development; structure, function and interactions of proteins, engineered enzymes, nucleic acid chemistry; chemical biology and biological chemistry; natural and chiral compounds; structural analysis, solid state analysis and electrochemistry; drug formulations, drug delivery systems and targeting; pharmacology and ADME; biomaterials and nanomaterials. The overview of various topics can be found within this special issue devoted to this conference. The aim of the conference was to facilitate contacts between scientists dealing with pharmaceutical sciences from the European and other countries and to support cooperation between scientists in this field. 
Great recognition is given to the Local Organising Committee, namely Prof. Milan Nagy, Dr. Pavol Jezko, Dr. Alexandra Plankova, Dr. Katarina Marakova, Dr. Renata Horakova, Dr. Jarmila Oremusova, Dr. Andrea Bilkova, and Ms. Jana Blahova who elaborately organized the conference. The organizers of ECDSA-2017 thank the following sponsors: Amedis, Lambda Life, Labo SK, Pragolab, Sotax, Hermes Lab Systems, Metrohm Slovensko, Angelini Pharma, VWR as well as Dr. Max, Infiniti Rock Cafe and Penzion Restauracia Janosikova Krcma.

Special gratitude is expressed to the Editors of Monatshefte fur Chemie-Chemical Monthly. The organizers express their deep gratitude to the Editor-in-Chief of the journal, Prof. Dr. Peter Gärtner and the Managing Editor, Dr. Christian Hametner for their generous consent to publish this issue and for their great support. The organizers thank all reviewers for valuable comments that helped to improve the quality of the manuscripts and the staff of the Publisher, Springer Vienna, for their contribution to the publication of the special issue.

Last but not least, the organizers thank all participants. Based on positive response, the organizers believe that ECDSA-2017 was beneficial for the participants and have the honour to invite them to the following EuroCongress on Drug Synthesis and Analysis in year 2020 that will be held again in the Slovak Republic. 